\title{
Analysis of the prospects of adopting the digital technology across sectors of the economy and its impact on the demand for energy carriers
}

\author{
Elena Galperova ${ }^{1 *}$, and Olga Mazurova ${ }^{1}$ \\ ${ }^{1}$ ESI SB RAS, Energy security Department, 664033 130, Lermontov Str., Irkutsk, Russia
}

\begin{abstract}
Projections of the demand for fuel and energy resources are an essential and fundamental part of the research that underpins the process of developing and making strategic-level decisions as applied to the national and regional energy and economic security. Identification, analysis, and study of the impact of factors and interrelationships in the energy and economy on the volume and structure of the demand for energy carriers is an integral part of the methodology for long-term projections of energy consumption. The use of the digital technology related to monitoring, acquisition, processing of large amounts of data across all sectors of the economy and everyday life of the population as of now already consumes more than $5 \%$ of electricity in the world and its further growth is expected. The study analyzes the possibilities of application of individual digital technologies in various sectors of the economy. Some estimates of their impact on demand for different types of fuel and energy resources are given. We note a great deal of uncertainty in the existing estimates of future energy consumption due to the government policy in this area, changes in the lifestyle patterns of the population, and the speed of development and adoption of technology innovations.
\end{abstract}

Keywords. Energy consumption, energy efficiency, energy saving, digital technology, data processing center, connected devices.

\section{Introduction}

The development of the global economy is accompanied by a growing demand for primary energy. It is estimated [1] that global primary energy consumption in the period between 2015 and 2040 may increase by $17-27 \%$ while that of electricity - by $60-70 \%$, despite energy saving and slowdown in growth rates.

Assessment of the prospective demand for different types of energy carriers is an important component of the development of programs and strategies of energy and economic development of the country and its regions, as well as policies to improve public welfare. Long-term projections of the demand for energy carriers is a multistage and multilevel process of studying the impact of factors and interrelationships under the changing conditions of energy and economic development on the volumes and structure of fuel and energy resources dynamics. One of the new factors of scientific and engineering progress that radically redefines the interrelation between energy consumers and energy producers is the introduction of the digital technology in the economy and energy industry [2-4]. At the SEI SB RAS, a methodological approach to long-term projections of demand for fuel and energy was developed [5] and is continuously updated [6,7]. Its further improvement is in the direction of factoring in the peculiarities of the development of intelligent electric power systems, in particular, the emergence of active consumers and studies of their impact on the levels of demand for electricity [8, 9]. However, the spread of digital technologies also affects other sectors of the economy, providing them with new opportunities for development and control. For this reason, the analysis of the prospects for the application of the digital technology in certain sectors of the economy and its impact on the level of demand for energy carriers becomes essential and relevant.

In recent decades, the world is experiencing global processes of digitalization of the economy, new infrastructure is being formed, new services are emerging to meet the growing needs of the population. The most important place in this process is occupied by digital technologies such as robotization, Internet of things, Big Data, artificial intelligence, blockchain, etc.

The rapid growth in the application of information and communication technologies in the economy was made possible by technological progress and the rapid cheapening of three components: data, analytics, and communication. The reduction in the cost of sensors (by more than 95\% since 2008) [10] led to their widespread adoption, explosive growth in the volume of available data, and the dissemination of digital information. Reducing the cost of computing power, the development of cloud technologies and Big Data, progress in deep analysis, including machine learning and artificial intelligence, opens up new opportunities for monitoring, analysis, and study of processes to obtain useful information, forming new knowledge and ideas. Reduced cost of data transfer through digital communication networks while increasing its speed, the development of technical capabilities to install data transmission and processing modules on transducers, sensors, and small devices, as well as the analysis of the received information create preconditions for mobile

* Corresponding author: galperova_e_v@mail.ru 
control of industrial, transportation, and domestic processes.

Nowadays, digital technologies are used in the industrial sector (to control processes and increase labor productivity and safety); in the transportation sector (to control traffic lights, collect passenger fare, identify the position on the road); and in residential and public buildings (to meter the use of energy resources and automatically control the operation of utilities and electrical appliances). The emergence and spread of technologies such as Internet of Things (IoT) and Internet of Services (IoS), smart home and smart city systems are transforming the requirements for running businesses, providing services, and housekeeping and are capable of drastically changing the model of the economy and prevailing lifestyle patterns.

\section{Prospects for the use of the digital technology across key sectors of the economy and its impact on energy demand}

\subsection{Industrial sector}

It is projected [11] that the share of the industrial sector in global energy consumption will decline from $40 \%$ in 2018 to $35 \%$ in 2050 . This decrease will be greatly facilitated by the spread of digital technologies at all stages of production, from direct process monitoring and control to business planning and document flow.

Creating a "digital twin" of real industrial enterprises allows accurately modeling the impact of innovation on changes in the existing production process, speeding up new product introduction to the market, saving time and resources during the design, development and optimization of new production processes.

The use of cloud platforms for the exchange of information of a particular industrial facility with its related enterprises, suppliers, and consumers allows utilizing assets as efficiently as possible and minimizing energy consumption for the transportation of materials and finished products [12].

The use of industrial robots and additive technologies (3D printing) can lead to significant energy savings and reduced resource consumption. Industrial robots improve the precision of manufacturing operations, reducing downtime and overheads. 3D printing enables both plastic and metal parts to be produced directly from digital files, which is instrumental in reducing lead times and scrap.

The potential for energy saving through the use of digital technologies in production process control varies significantly across individual industries depending on the type of activity, complexity of the production process, control systems, production culture, and the degree of integration of the enterprise in value chains (Figure 1).

Improved energy efficiency through the use of advanced digital process controls leads to significant energy savings. For example, in the USA, small industrial enterprises saved energy by more than USD 330 million over the period from 1987 to 2015 due to improved process control (Figure 2).

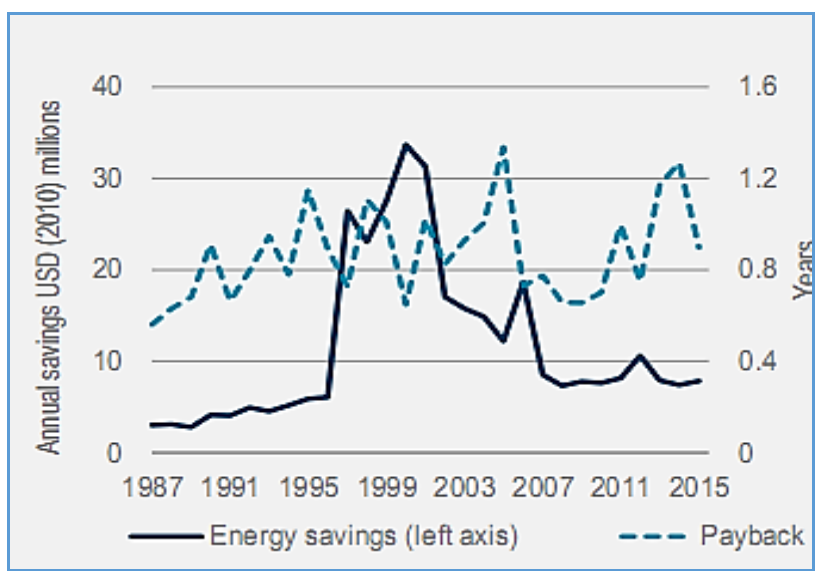

Source: [14]

Fig. 2. Energy savings in digitally enabled optimization of process controls in the United States.

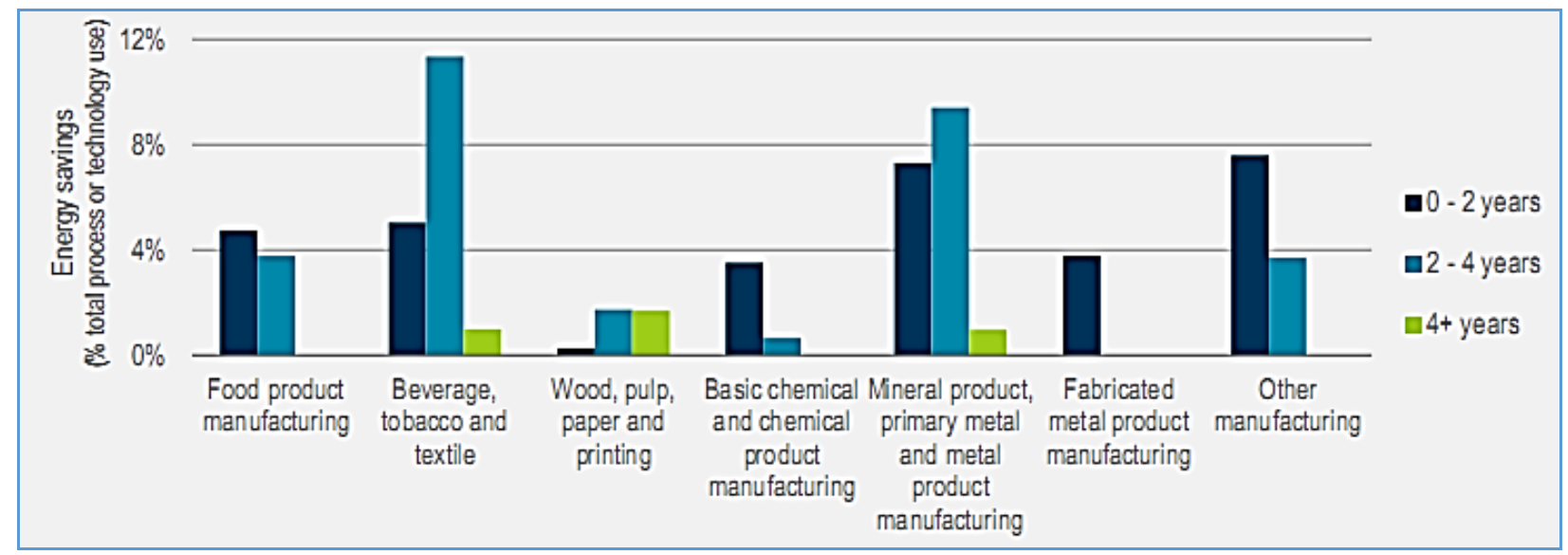

Source: [13]

Fig. 1. Potential energy savings from improvements in process control enabled by digitalization by subsector in Australia, 2010-11. 


\subsection{Transportation sector}

In 2018 , energy consumption by all modes of transport was about $40 \%$ of the final energy consumption in the world. The adoption of digital technologies helps to increase energy efficiency, reduce maintenance and operation costs of transport. Digitalization of all modes of transport will allow forming a new model of transport activity management, making the movement of passengers and cargo much smarter, more efficient, and more environmentally friendly [15].

The most revolutionary transformations can take place in road transport. Even now the global positioning system (GPS) helps in real-time to choose the right direction, speed and facilitates in rationalizing energy consumption by cars. The widespread dissemination of automation, communication technologies, car sharing services, along with further electrification can completely change the system of its organization. The experts hold [16] that in the long run, these transformations are capable of both reducing energy use in road transport by about half and increasing it by the same amount. The analysis of the scenarios developed by the U.S. Department of Energy for the long term [17], according to which the use of fuel and energy in automated vehicles can both be reduced by more than $90 \%$ and tripled, also shows considerable uncertainty in the estimates. Such a wide spread in prospective energy consumption estimates is associated with a high dependence on the scale of technology adoption, their interaction, the behavior patterns of the population, and the priorities of the government policy.

In railway transport, continuous control of the rolling stock operation conditions contributes to the reduction of fuel and electricity consumption. Automated driving technologies are already applied on high-speed and city lines, there are also fully automated trains. Automatic control that makes use of technologies of Big data and artificial intelligence will improve the operation of more trains based on the same infrastructure, optimize speed, increase volume, even out the traffic flow, improve performance, and reduce energy consumption.

In maritime transport, improved communication between ships and ports provides the opportunity to choose the optimal speed of the vessel in accordance with the requirements of the time of arrival at the port, which provides significant fuel savings.

In air transport, large data analysis helps optimize route planning, aids pilots in make decisions during the flight, and reduces fuel consumption. The use of unmanned aerial vehicles for civil and commercial purposes is still at an early stage of development, but with the widespread dissemination of this technology, cargo logistics and fuel demand may change significantly [18].

\subsection{Buildings}

It is projected [19] that the share of energy consumption by all types of buildings in global energy consumption will change from $20 \%$ in 2018 to $22 \%$ in 2050. Among other things, the use of active monitoring and control systems for energy supply to residential and commercial buildings helps contain energy consumption growth. The digital technology provide new opportunities for improving energy supply, increasing comfort and reducing overall energy consumption in buildings. Active control systems collect, process, and analyze data in real-time and allow controlling power consumption from a single interface panel (such as a smartphone or tablet). According to the IEA projection [16], increasing the operational efficiency of buildings using real-time data may reduce the total energy consumption by $10 \%$ in the period from 2017 to 2040 . This applies primarily to heating and air conditioning processes, where, thanks to the use of sensors and intelligent thermostats [20], potential energy savings can range from $15 \%$ to $50 \%$ (depending on the type of the building and control system).

Intelligent lighting [21], which consists of highperformance LEDs connected to building control systems, allows analyzing user preferences, illumination, building operation mode and provides a higher quality of lighting with significant energy savings. According to IEA estimates [16], in the period between 2017 and 2040 , intelligent lighting can save almost $20 \%$ of the total final energy consumption for lighting, in addition to the savings already brought by the widespread use of LEDs themselves. Moreover, commercial buildings account for most of the additional savings due to intelligent lighting (Figure 3). 


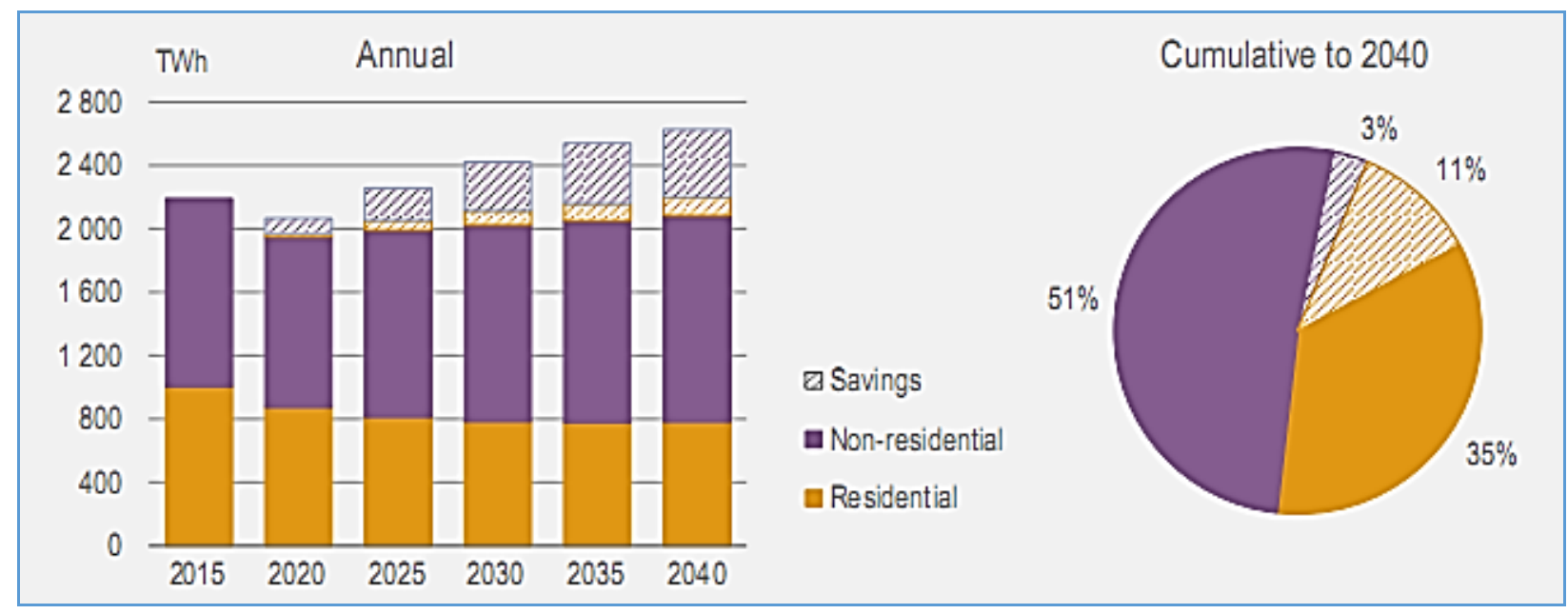

Source: [16]

Fig. 3. Potential electricity savings from smart lighting in buildings to 2040.

\subsection{Transformation of the electric power industry}

The use of digital technologies blurs the line between traditional energy suppliers and consumers and creates opportunities for consumers from all sectors of demand to participate directly in the energy system, balancing supply and demand in real-time [3]. This is ensured by the following: (1) the emergence of the consumer's ability to change their energy consumption depending on the situation in the energy system (demand response), (2) an increase in the share of prosumers who have their own sources of energy production or storage and contribute to the development of distributed energy resources, (3) the introduction of "smart charging" of electric vehicles, which switches the demand in off-peak periods (saving investment in new electricity infrastructure), (4) the use of new tools such as blockchain to facilitate the operation of the local system of energy trading [4].

The application of digital technology in the electric power industry is changing the entire business model of the industry, so that the concept of the Internet of Energy (IoE) has already taken off. Its characteristic features are:

- electricity production becomes distributed,

- electricity flows become bidirectional,

- "things" become participants in the new electricity market,

- energy is mobile and available anywhere, like mobile Internet.

\section{Energy consumption by information and communication technologies (ICT)}

The downside of the process of wide dissemination of digital technologies and the associated reduction of energy consumption across the sectors of the economy is the growth of energy consumption by ICT devices themselves. Even today, information and communication technologies, including data processing centers, data transfer networks and connected devices, have become important consumers of energy. In 2007-2012, the average annual growth rate of ICT energy consumption in the world was approximately $7 \%$, while the total growth rate was only $3 \%$ [16]. In 2012, global electricity consumption by the ICT sector was estimated at approximately 900 million $\mathrm{MWh}$, or $4.6 \%$ of total electricity consumption [22]. According to estimates presented in [23], currently ICT in the world accounts for $5-9 \%$ of total electricity consumption, and by 2030 it may increase to $20 \%$, though without factoring in the potential for efficiency improvements.

\subsection{Data processing centers}

Data processing centers (DPC) use energy to power both information technology equipment (servers, storage, network devices) and auxiliary infrastructure (e.g. cooling equipment). Energy consumption of data processing centers in the world doubles every 5 years and even now, according to different estimates, makes 3$5 \%$ of the total energy consumption in the world (Figure 4). At present, the issue of energy efficiency and energy saving opportunities in data processing centers is very urgent [24, 25].

The main directions of energy saving in data processing centers are [27]:

- optimization of the number of units of equipment: this reduces electricity consumption and decreases the amount of heat released;

- application of the free cooling system: this leads to reduction of energy costs;

- increase in acceptable temperature inside the data processing center: increase in temperature by one degree reduces the level of power consumption by $4-5 \%$;

- use of virtualization technology: (when a significant number of services are transferred to a small number of physical machines) this can save $10-40 \%$ of energy. 


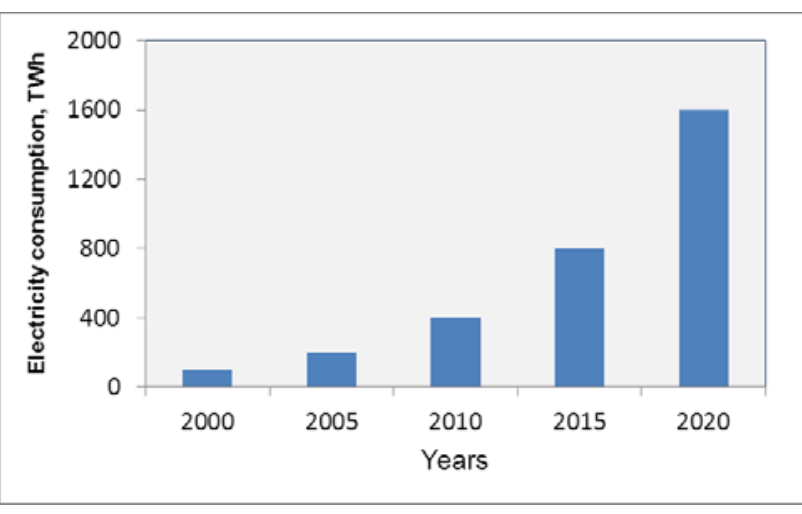

Source: [26]

Fig. 4. Dynamics of annual electricity consumption by data processing centers in the world.

Moreover, models are developed (see, for example, [28-30]) that describe the power consumption processes in cloud data centers by looking at static and dynamic parts of cloud components and showing how up to $20 \%$ of power consumption can be saved by following appropriate optimization directions.

\subsection{Data transmission networks}

Data transmission networks: they transfer information via fixed and mobile networks between two or more connected devices. In 2015, according to some estimates, they consumed $185 \mathrm{TWh}$ (1\% of total demand) of electricity. There is great uncertainty about the power consumption by data transmission networks. It is estimated that by 2021 electricity consumption in data transmission networks may increase by $70 \%$ or decrease by $15 \%$ depending on future trends in the efficiency improvement policy [16].

\subsection{Connected devices}

Connected devices and intelligent controls, including simple occupancy sensors and photo sensors, consume power to maintain communication even in standby mode [31] (Figure 5). For intelligent lighting, for example, the consumption varies from $0.15 \mathrm{~W}$ to $2.71 \mathrm{~W}$ per lighting fixture. Consequently, some connected lamps may consume more energy per year in standby mode than when actually used, reducing their net energy efficiency by more than half. Active control devices in the world in 2010 consumed about $2 \mathrm{kWh} / \mathrm{sq} . \mathrm{m}$. on average. It is expected that their continuous improvement and increased use will reduce the power intensity of active control devices by half in the next 25 years [16].

\section{Conclusion}

The digital technology is already used today across all sectors of the economy and everyday life of the population. Expansion of their use in the future changes the organizational and economic business model of production and provision of services and influences the demand for different types of energy carriers. ICTs are becoming an important energy consumer, whose prospective energy demand levels will be determined by the growth of data processing volumes and an increase in the efficiency of equipment used.

At present, there is a great deal of uncertainty in the estimates of the impact of digital technologies on energy demand in various industries and sectors of the economy, which is due to their great dependence on the priority directions of the government policy, lifestyle patterns, scale and speed of dissemination of technological progress. Further research in this area is a prerequisite for the modernization and development of available approaches to assessing the long-term dynamics of the demand for energy carriers.

The research was carried out under State Assignment 17.5.2 (reg. number AAAA-A17-117030310452-7) of the Fundamental Research of Siberian Branch of the Russian Academy of Sciences, some of the research findings were obtained being partially funded by RFBR project number 20 010-00204 and project number 18-010-00176.

\section{References}

1. Projection of the energy industry development in Russia and the world - 2019 / Ed. by A. A. Makarov, T.A. Mitrova, V.A. Kulagina (ERI RASMoscow School of Management SKOLKOVO, Moscow, 2019)

2. Filippov S.P. New technological revolution and energy requirements, Forsait. - Vol. 12. - No. 4 (2018), (in Russian)

3. Digitalization of the energy industry. Ministry of Energy of the Russian Federation. 2019. URL: https://minenergo.gov.ru/energynet/docs/Цифровая энергетика.pdf (Accessed on August 18, 2020). (in Russian)

4. The Future of Electricity New Technologies Transforming the Grid Edge. URL: http://www3.weforum.org/docs/WEF_Future_of_El ectricity_2017.pdf (Accessed on August 21, 2020).

5. Methods and models for projections of energyeconomy interactions / Yu. D. Kononov, E. V. Galperova, D. Yu. Kononov (Novosibirsk: Nauka, 2009) (in Russian)

6. Galperova E.V. Methodological approach to longterm projections of market demand for fuel and energy taking into account regional specifics and growing uncertainty // Izv. RAN. Energetika. No. 5 (2016) (in Russian)

7. Galperova E.V. Methodological tools for long-term projections of demand for energy carriers for different time stages of projection studies // Informacionnye i matematicheskie tekhnologii $\mathrm{V}$ nauke i upravlenii. No. 3(7) (2017) (in Russian)

8. Galperova E.V., Galperov V.I. Methodological approach to the study of the impact of smart energy systems development on electric power demand and price in the region // Informacionnye $\mathrm{i}$ matematicheskie tekhnologii $\mathrm{v}$ nauke i upravlenii. No. 1 (17) (2020) (in Russian) DOI: 10.38028/ESI.2020.17.1.004 


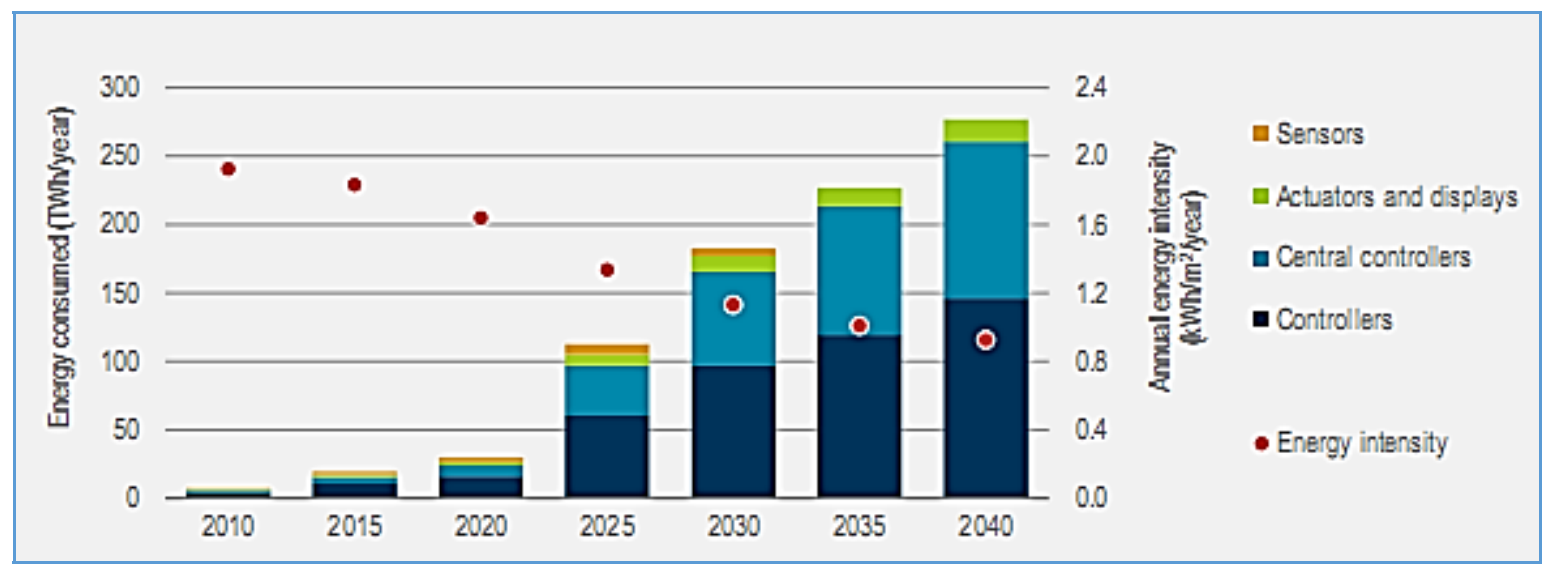

Source: [16]

Fig. 5. Global energy use and average energy intensity of active controls in buildings.

9. Gal'perova E.V. and Gal'perov V.I. Modeling the Active Consumer Behavior Based on the Agent Approach /2018 3rd Russian-Pacific Conference on Computer Technology and Applications (RPC) DOI: $10.1109 /$ RPC. 2018.8482157

10. In pursuit of energy efficiency. URL: http://www.energy2020.ru/news/news11805.php?sp hrase_id=71613 (Accessed on August 18, 2020). (in Russian)

11. International Energy Outlook 2019. URL: https://www.eia.gov/outlooks/ieo/ (Accessed on August 2, 2020)

12. Consolidation of the marke of SaaS marketplaces. URL: $\quad$ https://merlion.com/presscenter/press/5d7a24ea6e362 (Accessed on August 18, 2020). (in Russian)

13. Climate Works Australia (2013), Industrial Energy Efficiency Data Analysis Project. https://www.climateworksaustralia.org/resource/ind ustrial-energy-efficiency-data-analysis-projectieeda/

14. IAC (2017), IAC Database (database), https://iac.university/download.

15. The Future of Trucks: Implications for Energy and the Environment. (International Energy Agency OECD/IEA, Paris, 2017)

16. Digitalization \& Energy. (International Energy Agency OECD/IEA, 2017)

17. Brown, A., Gonder, J. and Repac, B. An Analysis of Possible Energy Impacts of Automated Vehicle. //Road Vehicle Automation (2014) URL: http://doi.org/10.1007/978-3-319-05990-7 13

18. Lyovin B.A., Bugaev A. S., Ivashov S.I., and Razevig V. V. Remotely piloted aircraft and route safety // Mir transporta. No. 2 (2013) (in Russian)

19. International Energy Outlook 2019. URL:https://www.eia.gov/outlooks/ieo/ (Accessed on August 2, 2020)

20. Energy Savings from the Next Learning Thermostat: Energy Bill Analysis Results (Nest Labs, 2015). URL: $\quad$ https://docplayer.net/2852386-Energysavings-from-the-nest-learning-thermostat-energybill-analysis-results.html (Accessed on August 2, 2020)
21. Kofod, C. Smart Lighting - New Features Impacting Energy Consumption. First Status Report. IEA 4E Solid State Lighting Annex Task 7 (2016). URL: https://ssl.iea-4e.org/ (Accessed on September 2, 2020)

22. Miller J., Bird L., Heeter J., and Gorham B. Renewable Electricity Use by the U.S. Information and Communication Technology (ICT) Industry. URL: https://www.nrel.gov/docs/fy15osti/64011.pdf (Accessed on August 21, 2020)

23. Between 10 and $20 \%$ of electricity consumption from the ICT* sector in 2030? URL: https://www.enerdata.net/publications/executivebriefing/expected-world-energy-consumptionincrease-from-digitalization.html (Accessed on August 21 2020)

24. Orlov S. Energy-saving technologies in the IT infrastructure of enterprises. URL: https://www.osp.ru/lan/2015/04/13045690 (Accessed on August 2, 2020). (in Russian)

25. Energy saving in the computer world. URL: http://portal-energo.ru/articles/details/id/890 (Accessed on September 3, 2020) (in Russian)

26. Tsarev I. PUE as a quality and energy efficiency criterion of the data processing center. URL: http://dcforum.ru/sites/default/files/12.10-12.30 pue kak_kriteriy kachestva.pdf (Accessed on August 19, 2020). (in Russian)

27. Bishop L. 4 Ways to Reduce Energy Consumption in Any Data Center. URL: https://blog.se.com/datacenter/2013/02/01/4-waysto-reduce-energy-consumption-in-any-data-center/ (Accessed on August 19, 2020)

28. Uchechukwu A., Li K., and Shen Y. Energy Consumption in Cloud Computing Data Centers. International Journal of Cloud Computing and Services Science (IJ-CLOSER) Vol.3, No.3 (2014)

29. Kliazovich D., Bouvry P., Granelli F., and Nelson L. S. da Fonseca. Energy Consumption Optimization in Cloud Data Centers URL: https://orbilu.uni.lu/bitstream/10993/18275/1/energy -management.pdf (Accessed on November 20, 2019) 
30. Popoola O, and Pranggono B. On energy consumption of switch-centric data center networks // The Journal of Supercomputing, Vol. 74, Is. 1 (2018)

31. Mohanty B. Standby Power Losses in Household Electrical Appliances and Office Equipment (2001). URL:

https://www.researchgate.net/publication/24212452 3 (Accessed on August 2, 2020) 